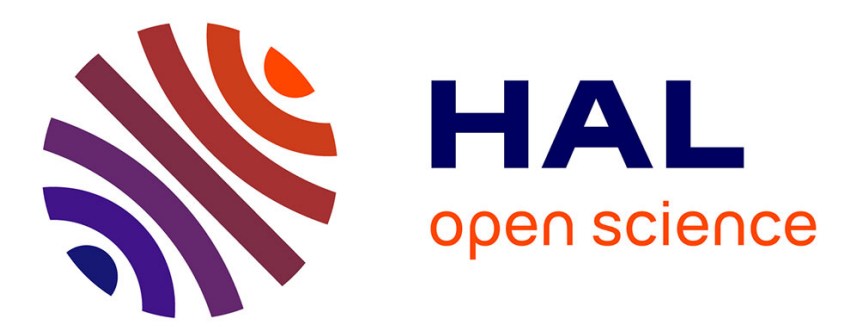

\title{
Hot-carrier degradation of CMOS inverters and ring oscillators at $77 \mathrm{~K}$
}

\author{
J.-T. Hsu, Xiaojian Li, P. Aum, D. Chan, C. Viswanathan
}

\section{To cite this version:}

J.-T. Hsu, Xiaojian Li, P. Aum, D. Chan, C. Viswanathan. Hot-carrier degradation of CMOS inverters and ring oscillators at 77K. Journal de Physique IV Proceedings, 1994, 04 (C6), pp.C6-37-C6-41. 10.1051/jp4:1994606 . jpa-00253100

\section{HAL Id: jpa-00253100 https://hal.science/jpa-00253100}

Submitted on 1 Jan 1994

HAL is a multi-disciplinary open access archive for the deposit and dissemination of scientific research documents, whether they are published or not. The documents may come from teaching and research institutions in France or abroad, or from public or private research centers.
L'archive ouverte pluridisciplinaire HAL, est destinée au dépôt et à la diffusion de documents scientifiques de niveau recherche, publiés ou non, émanant des établissements d'enseignement et de recherche français ou étrangers, des laboratoires publics ou privés. 


\title{
Hot-carrier degradation of CMOS inverters and ring oscillators at $77 \mathrm{~K}$
}

\author{
J.-T. Hsu, X. Li, P. Aum*, D. Chan* and C.R. Viswanathan
}

Department of Electrical Engineering, University of California, Los Angeles, CA 90024, U.S.A.

* SEMATECH, Austin, TX 78741-6499, U.S.A.

\begin{abstract}
The impact of hot-carrier (HC) stress on CMOS inverters at $77 \mathrm{~K}$ was examined as a function of temperature. It was found that the degradation in inverter propagation delay was about one order less than that of the device transconductance degradation. Activation energy $\left(E_{A}\right)$ of propagation delay exhibited two distinct values from $295 \mathrm{~K}$ to $77 \mathrm{~K}$, with a transition at around $175 \mathrm{~K}$ for virgin and stressed inverters. The improvement of propagation delay and voltage transfer characteristic (VTC) at $77 \mathrm{~K}$ compared to $295 \mathrm{~K}$ was larger for virgin than $\mathrm{HC}$ stressed inverters.
\end{abstract}

\section{INTRODUCTION}

It is well known that low temperature operation of MOSFET has significant advantages such as steeper subthreshold slope, higher transconductance, and lower junction capacitance [1]. It is also recognized that hot-carrier (HC) effects become more serious in low temperature operation. The study of low temperature $\mathrm{HC}$ stress has drawn considerable attention recently [2,3]. These studies were focused on discrete devices. In this paper, we present results of our studies concerning the effect of device hot-carrier degradation on the performance of CMOS inverters and ring oscillators at $77 \mathrm{~K}$. The motivation of this work is to investigate the effect of low temperature HC stress on circuit parameters and to examine the link between the degradation in device characteristics and circuit parameters. The circuit parameters such as inverter propagation delay $\left(t_{P}\right)$, ring oscillator frequency $\left(f_{O S C}\right)$, and voltage transfer characteristic (VTC) were measured as a function of temperature after applying $\mathrm{HC}$ stress at $77 \mathrm{~K}$. 


\section{EXPERIMENTAL}

CMOS inverters used in this study had $W / L$ of $10 / 0.6 \mu \mathrm{m}$ for nMOS and $20 / 0.6 \mu \mathrm{m}$ for pMOS. The driver nMOS transistors had a LDD with a gate oxide thickness of $120 \AA$ and a p-type substrate doping of $2 \times 10^{17} \mathrm{~cm}^{-3}$. While the load pMOS transistors had no LDD but had the same oxide thickness with a n-substrate of $2 \times 10^{17} \mathrm{~cm}^{-3}$. In our study of hot carrier stressed inverters, the stress was applied only to the driver (nMOS) transistor and not on the load (pMOS) transistor for the purpose of simplifying the interpretation of experimental results. Two types of hot-carrier stress were applied viz., Drain-Avalanche-Hot-Carrier (DAHC) stress with $\mathrm{VD} / \mathrm{VG}=8 / 4 \mathrm{~V}$ and Channel-Hot-Electron (CHE) stress with $V D / V G=8 / 8 \mathrm{~V}$. The stress was applied at $77 \mathrm{~K}$. The inverter propagation delay was measured as the average of the delay $t_{P H L}$ between the $50 \%$ point on the leading (rising) edge of the input pulse and the $50 \%$ point on the falling edge of the output pulse and the delay $t_{P L H}$ between the $50 \%$ point on the falling edge of the input pulse and the $50 \%$ point on the rising edge of the output pulse. The delay time measurement were carried out at different temperature after applying the stress at $77 \mathrm{~K}$.

The ring oscillators used in this study had 41 stages and the same W/L as those of inverters. While it was possible to access the driver in a single stage inverter to apply the stress and thereby study the effect of driver degradation on the inverter delay, it was not possible to access the individual transistors in the ring oscillator. A form of dynamic stress was applied on the transistors in the ring oscillator. The drain supply voltage $V_{D D}$ was kept at $8 \mathrm{~V}$. During the operation of the ring oscillator, the gate voltage is automatically switched between 0 and $8 \mathrm{~V}$ at the ring oscillator frequency.

\section{RESULTS AND DISCUSSION}

Propagation delay $t_{P}$, for CMOS inverters can be approximately expressed as:

$$
\begin{gathered}
t_{P H L}=\frac{C \Delta V}{I_{D N}} \\
t_{P L H}=\frac{C \Delta V}{I_{D P}} \\
t_{P}=\frac{t_{P H L}+t_{P L H}}{2}
\end{gathered}
$$

where $t_{P H L}$ and $t_{P L H}$ are the high-to-low and low-to high propagation delay respectively as defined earlier, $C$ is the output load capacitance, $\Delta V$ is equal to $1 / 2 V_{D D}$ for CMOS, $I_{D N}$ and $I_{D P}$ are the average drain current of nMOS and pMOS during the high-to-low and low-to-high transient, respectively. Fig. 1 shows the plot of normalized $I_{D N}$ and $I_{D P}$ as well as $1 / t_{P H L}, 1 / t_{P L H}$ and $1 / t_{P}$ as a function of temperature. $1 / t_{P H L}$ and $1 / t_{P L H}$ improve by approximately the same factor as $I_{D N}$ and $I_{D P}$, respectively as predicted by equations 1 and 2 . The improvement of average propagation delay $1 / t_{P}$ lies between those of $1 / t_{P H L}$ and $1 / t_{P L H}$ as expected. Fig.2 shows the degradation of 
$1 / t_{P H L}$, and transconductance $\left(g_{m}\right)$ plotted as function of stress time for DAHC and CHE stress at $77 \mathrm{~K}$. The degradation in $g_{m}$ in a device is about one order larger than that of the propagation delay in the inverter for both types of stress. DAHC stress shows larger degradation in both $g_{m}$ and $1 / t_{P H L}$ than CHE stress. While $g_{m}$ shows similar variation with respect to time under both types of stress, $1 / t_{P H L}$ exhibits much faster degradation in DAHC than in CHE stress. The difference is attributed to the fact that threshold voltage degradation at $77 \mathrm{~K}$ was observed to be larger in DAHC compared to CHE stress. Similar stress was applied to ring oscillator at $77 \mathrm{~K}$ with $V_{D D}$ equal to $8 \mathrm{~V}$. As shown in Fig. 2, the degradation in oscillation frequency $\left(f_{O S C}\right)$ in the ring oscillator is much lower compared to that of $1 / t_{P H L}$ in inverters. Similar result was reported earlier at room temperature for the comparison between single transistors and ring oscillators[4]. The difference in degradation rate is believed to be due to the dynamic stressing in ring oscillator.

The activation energy $\left(E_{A}\right)$ of propagation delay can be determined by plotting $\ln \left(t_{P H L}\right)$ as a function of $1 / T$ as shown in Fig.3. Two distinct activation energies can be inferred with a transition at around $175 \mathrm{~K}$ for virgin and stressed inverters. This shows that the improvement in propagation delay due to cooling is larger in the range between $295 \mathrm{~K}$ and $175 \mathrm{~K}\left(E_{A} \simeq 7 \mathrm{meV}\right.$ ) than below $175 \mathrm{~K}$ $\left(E_{A} \simeq 1.3 \mathrm{meV}\right)$. This behavior which is similar for virgin and stressed inverters can be explained as due to the dominance of impurity scattering at temperatures below $175 \mathrm{~K}$ in the inversion carrier mobility of VLSI devices with high substrate doping. It can be therefore inferred that the advantage of cooling is less than can be expected from the initial (high) activation energy. The existence of two activation energies has been reported for HC lifetime in individual devices [5].

The voltage transfer characteristics (VTC) were also investigated for both virgin and stressed inverters. Fig. 4 and Fig. 5 give the plots of VTC for temperatures ranging from $77 \mathrm{~K}$ to $295 \mathrm{~K}$ in virgin and DAHC stressed inverters, respectively. The DAHC stressed inverter shows less change in VTC as a function of temperature than the virgin inverter.

\section{CONCLUSION}

In conclusion, we investigated the effect on various circuit parameters of $\mathrm{HC}$ stress at $77 \mathrm{~K}$. DAHC stress shows larger degradation in $g_{m}$ and $t_{P H L}$ than CHE stress. $g_{m}$ degradation in a discrete device is larger than the propagation delay degradation in an inverter using that device. If the inverter lifetime is defined as the time for the propagation delay to decrease by a certain percentage with a similar definition for the lifetime of discrete device using decrease in $g_{m}$ as the defining parameter, our results show that the inverter lifetime is much larger that the discrete device lifetime. The activation energy of propagation delay exhibits two distinct values from $295 \mathrm{~K}$ to $77 \mathrm{~K}$ with a smaller energy below $175 \mathrm{~K}$. Both propagation delay and voltage transfer characteristics show larger improvement due to cooling for virgin inverters than for $\mathrm{HC}$ stressed inverters. 


\section{REFERENCES}

[1] F. Gaensslen, V. Rideout, E. Walker, and J. Walker, "Very Small MOSFET's for Low Temperature Operation", IEEE Trans. Electron Devices, vol.ED-24, p.218,1977

[2] P. Heremans, G. Van Den Bosch, R. Bellens, G. Groeseneken, and H. Maes, "Temperature Dependence of the Channel Hot-Carrier Degradation of n-Channel MOSFET's", IEEE Trans. Electron Devices, vol. ED-37, p.980, 1990.

[3] J. Tzou, C. Yao, R. Cheung, and H. Chan, "Hot-Electron-Induced MOSFET Degradation at Low Temperatures", IEEE Electron Device Letters, vol. EDL-6, p.450, 1985.

[4] K. Quader, P. Ko, and C. Hu, "Simulation of CMOS Circuit Degradation due to Hot-Carrier Effects", IEEE International Reliability Physics Symposium, p.16, 1992.

[5] M. Song, K. MacWilliams, J. Cable, and J. Woo, "Bias and Temperature Dependence of Hot Carrier Lifetime from 77K to 300K", IEEE International Electron Devices Meeting, p.707, 1992.

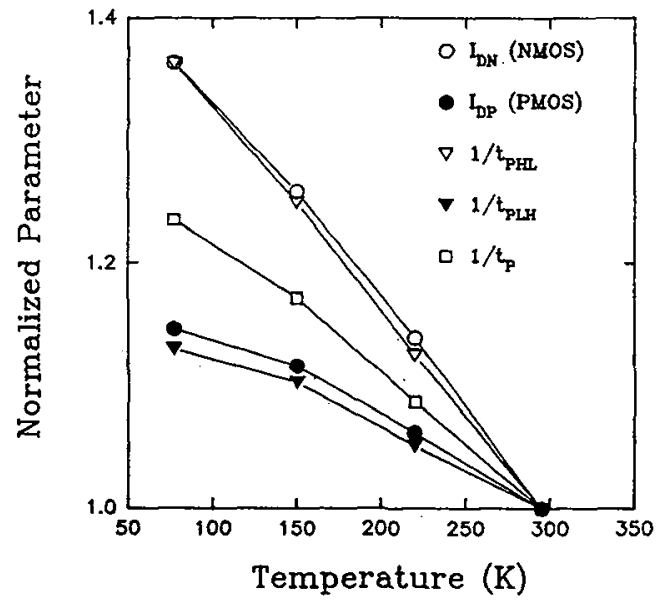

Fig.1 Plot of normalized $I_{D N}, I_{D P}, 1 / t_{P H L}$, $1 / t_{P L H}$ and $1 / t_{P}$ as a fun ction of temperature with respect to $295 \mathrm{~K}$ in a virgin inverter.

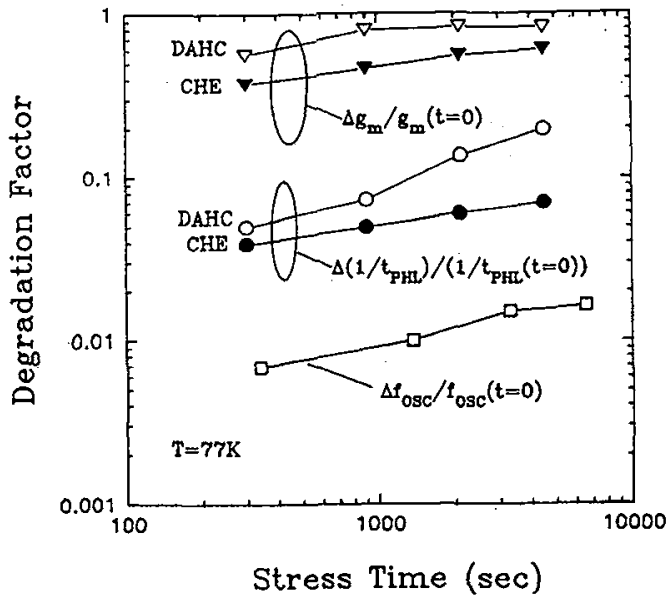

Fig.2 The degradation of $1 / t_{P H L}$ and $g_{m}$ in the inverters stressed by $\mathrm{DAHC}$ and $\mathrm{CHE}$ and the degradation of $f_{O S C}$ in a ring oscillator plotted as a function of stress time at $77 \mathrm{~K}$. 


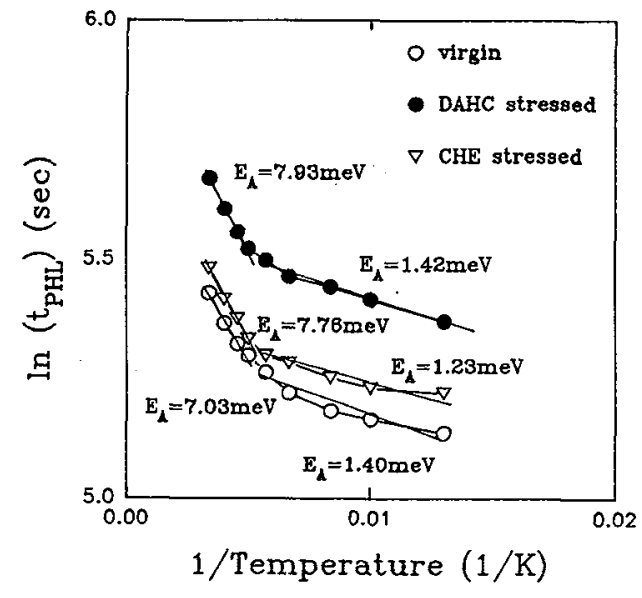

Fig.3 The activation energy $\left(E_{A}\right)$ of propagation delay extracted from virgin, DAHC, and CHE stressed inverters. Notice that there are two distinct $E_{A}$ in all three cases.

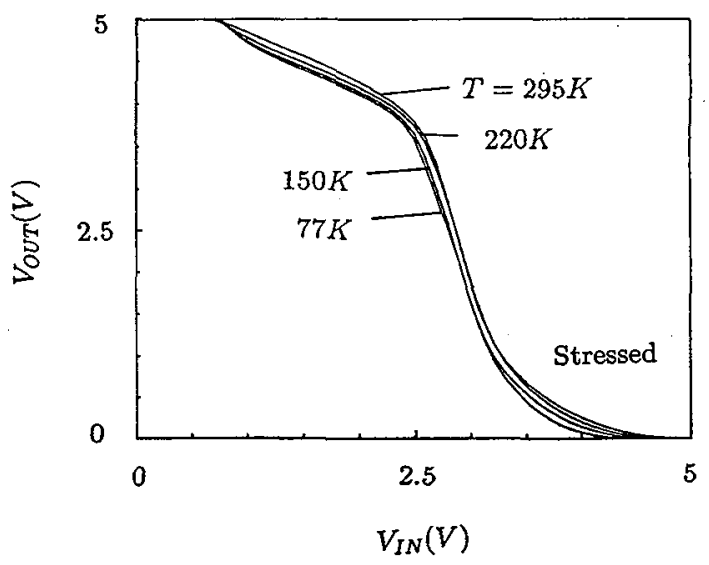

Fig.5 Plot of VTC for temperatures ranging from $77 \mathrm{~K}$ to $295 \mathrm{~K}$ in DAHC stressed inverter.

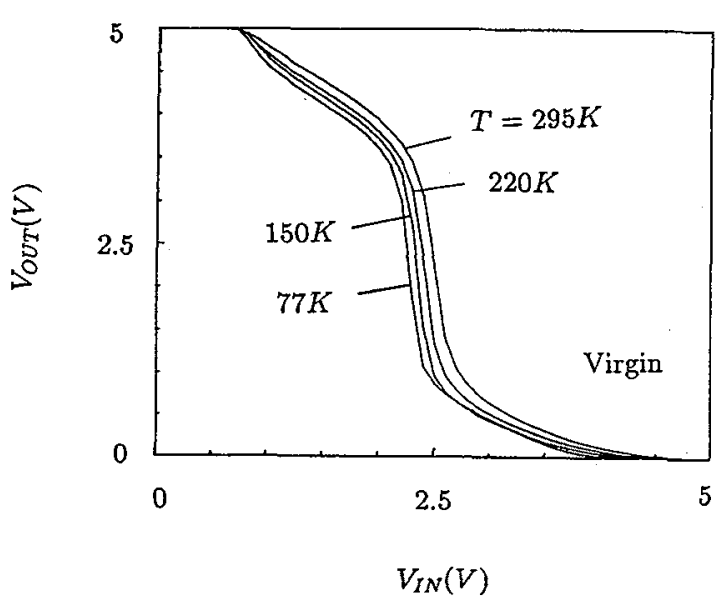

Fig.4 Plot of VTC for temperatures ranging from $77 \mathrm{~K}$ to $295 \mathrm{~K}$ in virgin inverter. 